\title{
Evaluation and enhancement of standard equations for renal function estimation in individuals with components of metabolic disease
}

\author{
Luigi Brunetti ${ }^{1,2,3^{*}}$, Hyunmoon Back${ }^{2}$, Sijia Yu², Urma Jalii ${ }^{4}$ and Leonid Kagan ${ }^{2,3}$
}

\begin{abstract}
Background: The primary objective of this study aims to test patient factors, with a focus on cardiometabolic disease, influencing the performance of the Cockcroft-Gault equation in estimating glomerular filtration rate.

Methods: A cohort study was performed using data from adult patients with both a 24-h urine creatinine collection and a serum creatinine available. Creatinine clearance was calculated for each patient using the Cockcroft-Gault, Modified Diet in Renal Disease, and Chronic Kidney Disease Epidemiology Collaboration equations and estimates were compared to the measured 24-h urine creatinine clearance. In addition, new prediction equations were developed.

Results: In the overall study population $(n=484), 44.2 \%$ of patients were obese, $44.0 \%$ had diabetes, and $30.8 \%$ had dyslipidemia. A multivariable model which incorporating patient characteristics performed the best in terms of correlation to measured 24-h urine creatinine clearance, accuracy, and error. The modified Cockcroft-Gault equation using lean body weight performed best in the overall population, the obese subgroup, and the dyslipidemia subgroup in terms of strength of correlation, mean bias, and accuracy.
\end{abstract}

Conclusions: Regardless of strategy used to calculate creatinine clearance, residual error was present suggesting novel methods for estimating glomerular filtration rate are urgently needed.

Keywords: Cockcroft-Gault, Renal function, Metabolic disease, Serum creatinine, Glomerular filtration rate

\section{Introduction}

Creatinine clearance $(\mathrm{CrCl})$ is used to estimate glomerular filtration rate (GFR) to assess renal function. Numerous medications require dosage adjustment in the setting of reduced GFR and $\mathrm{CrCl}$ is often used to guide dosing of medications cleared by the kidney. The most accurate and clinically feasible estimate of $\mathrm{CrCl}$ is the measured 24-h urine $\mathrm{CrCl}$; however, this method is not often practical

\footnotetext{
*Correspondence: brunetti@pharmacy.rutgers.edu

${ }^{3}$ Center of Excellence in Pharmaceutical Translational Research and Education; Ernest Mario School of Pharmacy; Rutgers, The State University of New Jersey, Piscataway, NJ, USA

Full list of author information is available at the end of the article
}

and is time consuming. The Cockcroft-Gault equation published in 1976, [1] is the most commonly used formula to calculate $\mathrm{CrCl}$ using serum creatinine in the clinical setting. This equation was derived from a primarily Caucasian male population aged $18-92$ years. While simple and in clinical use for more than 4 decades, there are several limitations one must acknowledge with the use of this formula. First, the population in 1976 was very different from the present-day population where over onethird of US adults are considered overweight or obese [2]. Further, in 2015, an estimated 30 million Americans were diagnosed with type 2 diabetes mellitus and continued increases in prevalence are expected $[3,4]$. Both animal 
and human studies provide evidence that atherogenic lipid profile influences glomerular sclerosis and renal dysfunction, respectively, making dyslipidemia a relevant consideration in evaluating renal function estimates [5, 6]. Both obesity and diabetes are associated with altered muscle mass, $[7,8]$ which may influence serum creatinine a key variable in the Cockcroft-Gault equation. Another consideration is that the population used to derive the equation was primarily male (96\%) and the extrapolation of the equation to females was based on estimates rather than objective data. Finally, the relatively small sample included in the study did not allow for subgroup analysis to determine in what populations calculated $\mathrm{CrCl}$ was not accurate.

The appropriate assessment of renal function is critical for drug dosing. More than half of all medications are cleared by the kidneys and inappropriate dose adjustment to account for potential drug accumulation may lead to drug toxicity. Therefore, an adept understanding of the accuracy, reliability, and nuances of the CockcroftGault equation is necessary. Moreover, strategies to correctly classify the degree of renal dysfunction are likely to improve patient outcomes. The reliability and application of the Cockcroft-Gault equation (see equation below)

$$
\frac{(140-\text { age in years }) * \text { total body weight in } \mathrm{kg}}{72 * s C r(\mathrm{mg} / \mathrm{dL})} * 0.85 \text { if female }
$$

in clinical practice may be influenced by several factors. First, the impact of weight must be considered. The physiological max GFR is approximately $120 \mathrm{~mL} / \mathrm{min}$; however, if the total body weight of an obese patient is entered into the equation the resultant value for $\mathrm{CrCl}$ often exceeds this threshold [9-11]. The question arises as to whether we should use ideal, lean, adjusted, or total body weight; a question that has been frequently tested with different answers [9-14]. The original CockcroftGault equation suggested total body weight - but this was before the worldwide obesity epidemic. Second, serum creatinine may be influenced by malnutrition, cachexia, liver disease, and other conditions leading to lower muscle mass $[13,15,16]$. In clinical practice, serum creatinine is often below $1.0 \mathrm{mg} / \mathrm{dL}$ in these populations; therefore, GFR tends to be overestimated by the Cockcroft-Gault equation. Some have suggested rounding serum creatinine to $0.8 \mathrm{mg} / \mathrm{dL}$ or $1 \mathrm{mg} / \mathrm{dL}$ to account for this concern [17]. There is no substantial evidence to support these suggestions [17]. Overall, the aforementioned limitations are evident in individuals with components of cardiometabolic disease (i.e., obesity and diabetes). These individuals have altered body composition and as such estimates of renal function may less accurate. The primary objective of this study aims to test patient factors, with a focus on cardiometabolic disease, influencing the performance of the Cockcroft-Gault equation in estimating GFR. The secondary objectives were to determine if the development of a new $\mathrm{CrCl}$ equation by either modification of the original Cockcroft-Gault equation or using nonlinear regression incorporating disease states and race improved estimation relative to measured 24-h urine $\mathrm{CrCl}$.

\section{Methods}

\section{Data source and patient selection}

A retrospective cohort study was performed using data extracted from the electronic discharge database and medical records at community medical center between January 2009 and July 2019. All consecutive adult patients (aged 18 years or older) with both a 24-h urine creatinine collection and a serum creatinine obtained within $24 \mathrm{~h}$ of each other were screened for inclusion. The institutional standard for measurement of creatinine is the Jaffe method. Only patients with comorbidities recorded in the electronic health record were further considered for inclusion. Patients were required to have a stable serum creatinine defined as less than a $20 \%$ fluctuation between two serum creatinine values measured within $48 \mathrm{~h}$. Patients who were pregnant, had undergone amputations, in acute renal failure, or those on hemodialysis were excluded. Individuals with a serum creatinine greater than $2.5 \mathrm{mg} / \mathrm{dL}$ were excluded from the analysis since this would suggest Stage 5 Chronic Kidney Disease and previous data reported inaccuracies in estimation of $\mathrm{CrCl}$ using traditional equations in this population $[18,19]$. Patients with a serum creatinine $<0.6 \mathrm{mg} / \mathrm{dL}$ were excluded since low serum creatinine may result in significant overestimates of renal function. Individuals with a measured $24-\mathrm{h}$ urine $\mathrm{CrCl}$ below $10 \mathrm{~mL} / \mathrm{min}$ were excluded since it would be expected that those in this group would receive dialysis [20].

\section{Data extraction and collection}

All data were extracted from the patient discharge database and electronic health records (Cerner Millennium and Allscripts, Sunrise Clinical Manager). Patient height, weight, age, sex, race, and laboratory data were extracted from the medical record. Patient comorbidities were identified using International Classification of Diseases, 9th Revision or Clinical Modification or International Classification of Diseases, 10th Revision, Clinical Modification codes depending on availability. Once data were extracted, lean body weight, ideal body weight, and adjusted body weight were calculated based on standard equations [21-27]. Subsequently, $\mathrm{CrCl}$ was calculated using the Cockcroft-Gault equation. Various weight descriptors were then used for different versions of the 
Cockcroft-Gault equation. Some authors suggest rounding the $\mathrm{sCr}$ to $1.0 \mathrm{mg} / \mathrm{dL}$ if less than $1.0 \mathrm{mg} / \mathrm{dL}$, especially in patients $>65$ years of age. Therefore, calculated $\mathrm{CrCl}$ with the original Cockcroft-Gault equation was computed using $\mathrm{sCr}$ rounded to $1.0 \mathrm{mg} / \mathrm{dL}$ if less than $1.0 \mathrm{mg} /$ dL. $\mathrm{CrCl}$ was also computed using the Modified Diet in Renal Disease (MDRD) and Chronic Kidney Disease Epidemiology Collaboration (CKD-EPI) equations other commonly used equations for estimating renal function [28-30]. All the standard equations used to estimate GFR are summarized in Table $1[1,28,29,31]$.

\section{New equation development}

Measured 24-h urine $\mathrm{CrCl}$ was used as the reference value to construct a prediction equation. All the equations derived for the prediction of $\mathrm{CrCl}$ were estimated using nonlinear regression. To consider sex effect of equation performance, the coefficient values for each male and female were estimated. Further, the effect of disease status on the equation performance was tested and selected based on the calculated $p$ value from nonlinear regression. To develop a new $\mathrm{CrCl}$ equation, two strategies were considered. First, we considered modification of the Cockcroft-Gault equation. The coefficient values in the original Cockcroft-Gault eq. (72, 140, and 0.85 for women) were re-estimated using total body weight or lean body weight for each sex and then effect of disease state (obesity, diabetes, and dyslipidemia) was included.

We also considered substitution of various estimates of lean body weight in the Cockcroft-Gault equation. While the James equation for lean body weight estimation is commonly used due to its brevity, the Hume equation has been suggested as the optimal choice in special populations including obese patients (those with a body mass index [BMI] index above $37 \mathrm{~kg} / \mathrm{m}^{2}$ ) [32]. We placed preference on this equation; however, tested others through construction and visual inspection of surface area plots and the influence this weight descriptor had on the performance of the Cockcroft-Gault equation versus measured 24-h urine $\mathrm{CrCl}$.

Second, we performed multivariate regression analysis. For multivariate eq. 1, measured 24 -h urine $\mathrm{CrCl}$ was divided by body surface area and then coefficient values for serum creatinine, age, and sex were estimated. For multivariate eqs. 2, 3, and 4 total, adjusted, or lean body weight were included with coefficient values to develop equation, respectively, as well as serum creatinine, age, and sex. After estimating coefficient values from base equations, disease states (obese, diabetes, and dyslipidemia) and race (white or non-white) were tested and included if $p<0.05$ in the regression analysis. Only disease states present in at least $15 \%$ of patients in the analytic dataset were considered for evaluation in the regression.

\section{Statistical analysis}

All results were summarized using descriptive statistics. Mean and standard deviation were reported for normally distributed continuous data and median and range were reported for data that were not normally distributed. Normality of data was assessed using visual inspection of histograms and the Shapiro-Wilk test. Binary data were reported as counts and proportions. The Pearson's correlation coefficient between each of the calculated $\mathrm{CrCl}$ values and the measured 24- $\mathrm{h}$ urine $\mathrm{CrCl}$ and corresponding $95 \%$ confidence intervals were calculated using

Table 1 Methods for calculating or measuring creatinine clearance

\begin{tabular}{|c|c|}
\hline Method & Equation \\
\hline Cockcroft-Gault & $\begin{array}{l}\frac{(140-\text { age in years)*weight in } \mathrm{kg}}{72 * s \mathrm{Cr}(\mathrm{mg} / \mathrm{dL})} \\
\text { Multiply by } 0.85 \text { if female } \\
\text { Original equation used total body weight }\end{array}$ \\
\hline $\mathrm{CKD}-\mathrm{EPI}$ & $\begin{array}{l}141 * \min \left(\frac{s c r}{k}, 1\right) \alpha * \max \left(\frac{s c r}{k}, 1\right)^{-1.209} * 0.933^{a g e} * 1.018^{\text {if female }} * 1.159^{\text {if } \text { African American }} \\
\text { Where: } \\
\mathrm{s} C r \text { is serum creatinine in } \mathrm{mg} / \mathrm{dL} \\
\mathrm{k} \text { is } 0.7 \text { for females and } 0.9 \text { for males } \\
\mathrm{a} \text { is }-0.329 \text { for fema } \mathrm{es} \text { and }-0.411 \text { for males } \\
\text { min indicates the minimum of } \mathrm{s} \mathrm{Cr} / \mathrm{k} \text { or } 1 \\
\text { max indicates the maximum of } \mathrm{s} \mathrm{Cr} / \mathrm{k} \text { or } 1\end{array}$ \\
\hline MDRD & $175 * s \mathrm{Cr}^{-1.54} * \mathrm{Age}^{-.203} * 0.742$ (iffemale) $* 1.212$ if African American \\
\hline
\end{tabular}


Fishers $\mathrm{Z}$ methods. The mean bias between the measured 24- $\mathrm{h} \mathrm{CrCl}$ and various methods for calculated $\mathrm{CrCl}$ was defined as the difference between the two values and the precision was described using the 95\% confidence interval for the difference. Root mean square error (RMSE) was calculated for each outcome in order to assess the degree of bias. Calculated $\mathrm{CrCl}$ not deviating more the $30 \%$ from the 24-h urine $\mathrm{CrCl}$ was considered to be accurate. This definition of accuracy was based on the original study validating the Cockcroft-Gault equation, which reported that Cockcroft-Gault calculated $\mathrm{CrCl}$ was within $30 \%$ of the $24-\mathrm{h}$ urine $\mathrm{CrCl}$ [1] and others suggesting that if calculated $\mathrm{CrCl}$ is within $25 \%$ of measured $24 \mathrm{~h}$ urine $\mathrm{CrCl}$ it is considered accurate [18]. All analyses were conducted using SPSS, version 26 (IBM Corporation, Somers, NY) and R (R Core Team, Vienna, Austria).

\section{Results}

Figure 1 provides an overview of the patient selection process. After the initial screening, 687 patients were included in the dataset; however, upon application of the inclusion and exclusion criteria the final analytic dataset included 484 patients. Table 2 provides a summary of the patient characteristics. In the overall population, $44.2 \%$ of patients were obese, $44.0 \%$ had diabetes, and $30.8 \%$ had dyslipidemia. The mean calculated $\mathrm{CrCl}$ ranged from $55.8 \pm 28.0 \mathrm{~mL} / \mathrm{min}$ to $77.8 \pm 37.2 \mathrm{~mL} / \mathrm{min}$ depending on the method used. For comparison, the mean measured 24-h urine $\mathrm{CrCl}$ was $85.1 \pm 47.5 \mathrm{~mL} / \mathrm{min}$. Depending on the subgroup (obese, diabetes, or dyslipidemia) there was variation in the mean calculated $\mathrm{CrCl}$ (Table 2). Using the traditional equations, adjusted and lean body weight produced the strongest correlation coefficients in the overall population and subgroups. Total body weight was similar and outperformed the other weight descriptors in terms of mean bias. Finally, adjusted body weight produced the greatest accuracy in most cases. Of the newly developed equations, multivariate (MVA) 4 which incorporated lean body weight, select diseases, sex, and race performed the best in terms of correlation to measured 24-h urine $\mathrm{CrCl}$, accuracy, and RMSE value (Table 3). This equation was further tested versus the other MVA equations. In addition, a modified Cockcroft-Gault equation was developed using the available data (Fig. 2). This

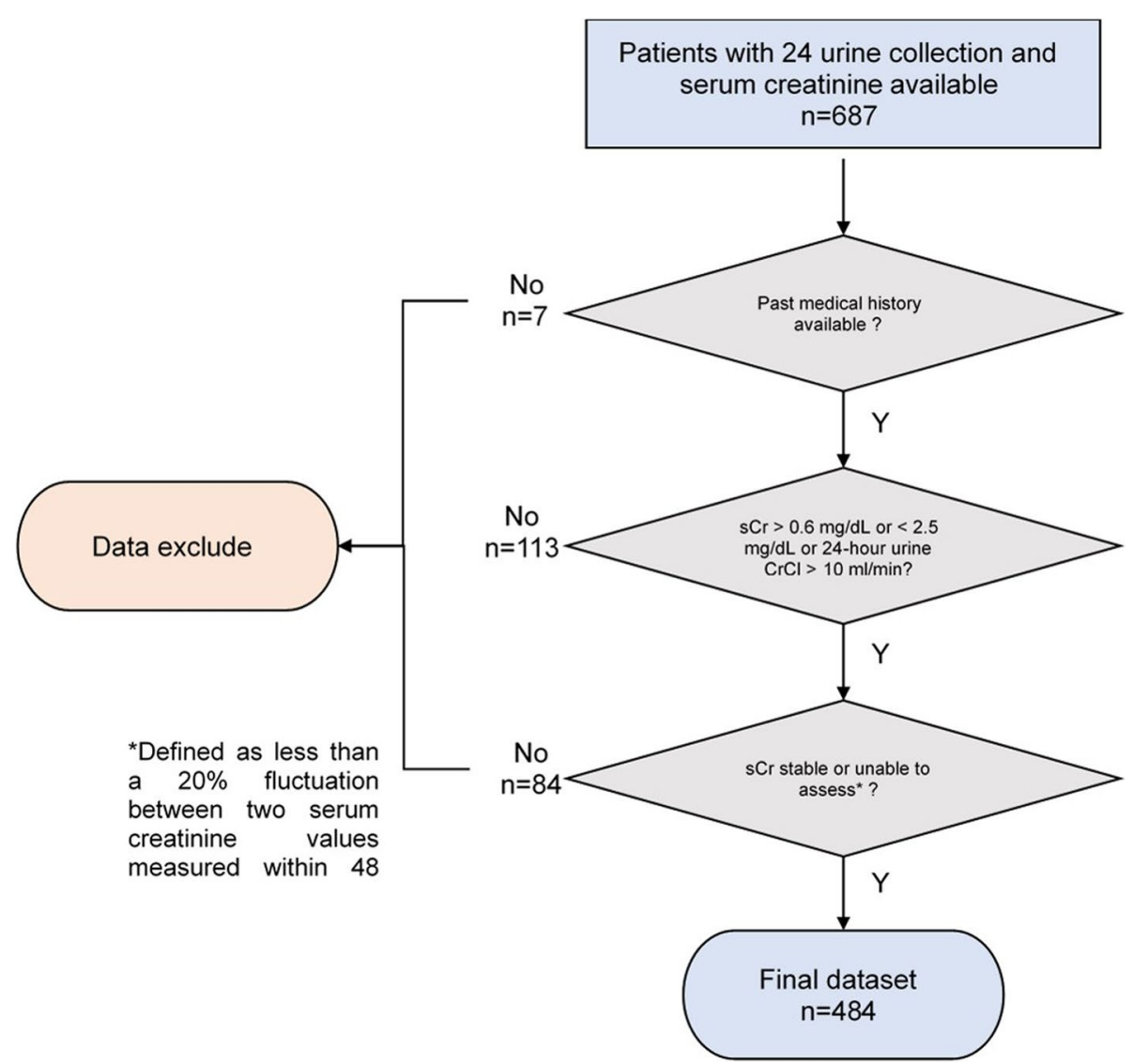

Fig. 1 Data inclusion decision tree for evaluating various methods of calculating creatinine clearance 


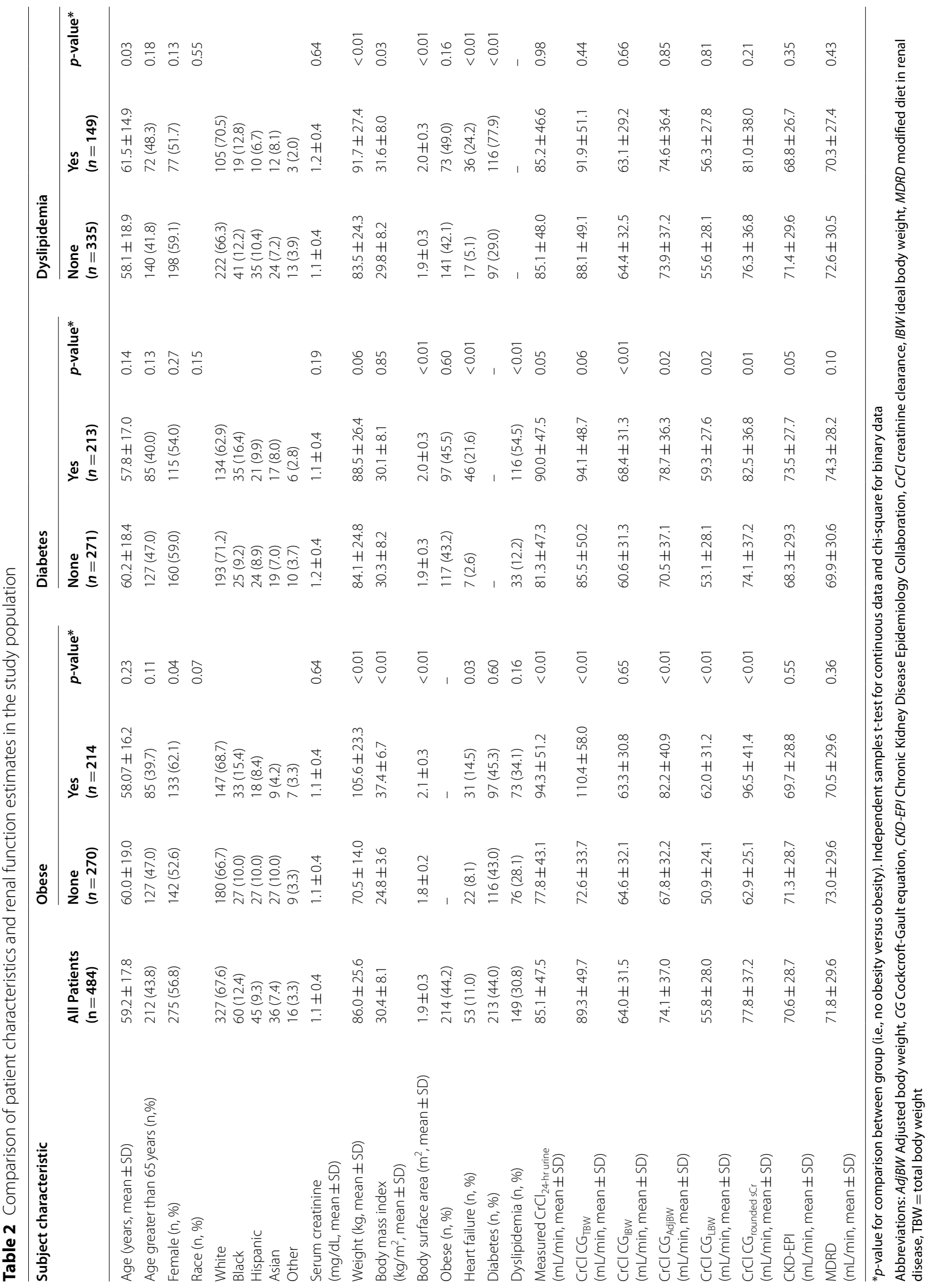


equation incorporated obesity, diabetes, dyslipidemia, sex, and lean body weight. The correlation coefficient, mean bias, accuracy, and RMSE of each calculated $\mathrm{CrCl}$ method (including newly developed methods) versus the measured 24-h urine $\mathrm{CrCl}$ for the overall population and each subgroup is summarized in Table 4. The modified Cockcroft-Gault equation using lean body weight calculated using the Hume method performed best in the overall population, the obese subgroup, and the dyslipidemia subgroup in terms of strength of correlation, mean bias, and accuracy. The Cockcroft-Gault equation using adjusted body weight performed best in the diabetes subgroup.

\section{Discussion}

The estimation of GFR using calculated $\mathrm{CrCl}$ is critical to select optimal medication dosing regimens. Individuals with obesity, diabetes, and dyslipidemia often are on many medications and have altered kidney function making calculating $\mathrm{CrCl}$ more critical. The overall purposes of this study were to identify the influence of cardiometabolic disease on GFR estimation and to enhance and develop $\mathrm{CrCl}$ equations. The current study identified several limitations with current practices in the calculation of $\mathrm{CrCl}$. First, the Cockcroft-Gault equation uses the total body weight in calculating $\mathrm{CrCl}$. There has been conflicting data regarding substituting adjusted body weight into the equation. We provide evidence that adjusted body weight is a reasonable consideration. Using this weight produced similar and, in some situations, better correlation, lower bias, and improved accuracy. Moreover, we demonstrate that the inclusion of obesity, diabetes, dyslipidemia, and race into a modified Cockcroft-Gault equation improves performance relative to the original Cockcroft-gault equation.

Previous studies have investigated the precision, bias, and accuracy or overall performance of GFR estimation using calculated $\mathrm{CrCl}$ in a variety of populations $[11,12$, $16,17,31,33,34]$. Our study is the first to consider all the components of cardiometabolic syndrome. The implications are significant in that the number of individuals with diabetes and obesity has continued to rise in the US and worldwide $[2,4,35,36]$. Moreover, many early equations were developed in primarily Caucasian populations, leaving for debate whether the accurately capture the population as a whole. As such, we should ensure that validated equations still apply to the current population.

Some limitations to our study must be considered. First, 24-h $\mathrm{CrCl}$ was used as the reference value, an alternate to the gold standard. Ideally, injection of inulin and capturing its clearance by the kidneys would be preferable; however, this approach is seldom applied in the clinical setting due to its invasiveness, cost, time commitment, and lack of availability in retrospective data

Table 3 Development and testing of multivariate equations to calculate

\begin{tabular}{|c|c|c|}
\hline Model & Equation & $\begin{array}{l}\text { Correlation } \\
\text { coefficient / } \\
\text { RMSE }\end{array}$ \\
\hline MVA 1 & $154.727 \times B S A \times \mathrm{Scr}^{-0.937} \times a g e^{-0.301} \times 0.872^{\text {Sex }} \times 0.983^{\text {Race }} \times 1.042^{\text {Diabetes }} \times 1.050^{\text {Obesity }} \times 0.971^{\text {Dyslipidemia }}$ & $0.78 / 29.89$ \\
\hline MVA 2 & $5.466 \times \mathrm{TBW}^{0.976} \times \mathrm{SCr}^{-0.919} \times$ age $^{-0.359} \times 0.926^{\text {Sex }} \times 1.003^{\text {Race }} \times 1.034^{\text {Diabetes }} \times 0.804^{\text {Obs }} \times 0.957^{\text {Dyslipidemia }}$ & $0.79 / 29.25$ \\
\hline MVA 3 & $0.985 \times \mathrm{AdjBW}^{1.356} \times \mathrm{Scr}^{-0.924} \times$ age $\mathrm{e}^{-0.314} \times 1.014^{\text {Sex }} \times 0.970^{\text {Race }} \times 0.998^{\text {Diabetes }} \times 0.924^{\text {Obesity }} \times 0.964^{\text {Dyslipidemia }}$ & $0.80 / 28.65$ \\
\hline MVA 4 & $1.431 \times L B W^{1.360} \times \mathrm{Scr}^{-0.920} \times$ age $\mathrm{-}^{-0.318} \times 1.043^{\text {Sex }} \times 0.976^{\text {Race }} \times 0.999^{\text {Diabetes }} \times 0.913^{\text {Obesity }} \times 0.963^{\text {Dyslipidemia }}$ & $0.80 / 28.65$ \\
\hline
\end{tabular}

Abbreviations: AdjBWadjusted body weight, BSAbody surface area, LBWlean body weight calculated using the Hume equation, MVAmultivariate, TBWtotal body weight. MVA 4 was selected for further development based on strength of correlation coefficient and RMSE value versus measured $24-\mathrm{h}$ urine $\mathrm{CrCl}$

$$
C r C l_{\text {Male }}=\frac{(194.385-\text { age }) * L B W * 1.022^{\text {DM }} * 0.949^{\text {Obese }} * 0.931^{\text {Dyslipidemia }} * 1.046^{\text {Race }}}{82.812 * s C r}
$$

$\operatorname{CrCl}_{\text {Female }}=\frac{(182.643-\text { age }) * L B W * 1.013^{\text {DM }} * 1.036^{\text {Obese }} * 1.010^{\text {Dyslipidemia }} * 0.959^{\text {Race }}}{79.138 * s C r}$

Fig. 2 Modification of the Cockcroft-Gault equation to include select disease states and race 
Table 4 Correlation, bias, and accuracy between measured (24-h urine) glomerular filtration rate and estimated glomerular filtration rate is select populations

\begin{tabular}{|c|c|c|c|c|c|}
\hline Method & Mean $\mathrm{CrCl} \pm \mathrm{SD}$ & $\begin{array}{l}\text { Correlation coefficient } \\
(95 \% \mathrm{Cl})\end{array}$ & $\begin{array}{l}\text { Mean bias } \\
(95 \% \mathrm{Cl})\end{array}$ & $\begin{array}{l}\text { Accuracy } \\
\text { within } \pm 30 \% \\
n(\%)\end{array}$ & RMSE \\
\hline \multicolumn{6}{|l|}{ Overall $(n=484)$} \\
\hline $\mathrm{CrCl} C G_{A B W}$ & $89.3 \pm 49.7$ & $0.77(0.73-0.80)$ & $-4.2(-7.2-1.2)$ & $295(61.0)$ & 33.49 \\
\hline $\mathrm{CrCl} C G_{I B W}$ & $64.0 \pm 31.5$ & $0.72(0.67-0.76)$ & $21.1(18.2-24.1)$ & $224(46.3)$ & 39.13 \\
\hline $\mathrm{CrCl} \mathrm{CG}_{\mathrm{AdjBW}}$ & $74.1 \pm 37.0$ & $0.78(0.74-0.81)$ & $11.0(8.3-13.6)$ & $298(61.6)$ & 31.56 \\
\hline $\mathrm{CrCl} \mathrm{CG}_{\mathrm{LBW}}$ & $55.8 \pm 28.0$ & $0.78(0.74-0.81)$ & $29.3(26.5-32.1)$ & $162(33.5)$ & 42.72 \\
\hline $\mathrm{CrCl} \mathrm{CG}_{\text {rounded s } \mathrm{Cr}}$ & $77.8 \pm 37.2$ & $0.73(0.69-0.77)$ & $7.3(4.4-10.3)$ & $289(59.7)$ & 62.26 \\
\hline CKD-EPI & $70.6 \pm 28.7$ & $0.68(0.63-0.73)$ & $14.5(11.4-17.6)$ & $256(52.9)$ & 37.88 \\
\hline MDRD & $71.8 \pm 29.6$ & $0.64(0.58-0.69)$ & $13.3(10.0-16.5)$ & $250(51.7)$ & 40.45 \\
\hline $\mathrm{CrCl} \mathrm{CG}$ modified & $85.4 \pm 37.2$ & $0.78(0.74-0.81)$ & $0.2(-2.4-2.9)$ & $300(62.0)$ & 28.48 \\
\hline MVA & $75.9 \pm 26.9$ & $0.77(0.73-0.80)$ & $4.2(1.2-7.2)$ & $282(58.3)$ & 28.65 \\
\hline \multicolumn{6}{|l|}{ Obesity $(n=214)$} \\
\hline $\mathrm{CrCl} C G_{A B W}$ & $110.4 \pm 58.0$ & $0.78(0.72-0.83)$ & $-16.1(-21.0--11.2)$ & $129(60.3)$ & 39.89 \\
\hline $\mathrm{CrCl} \mathrm{CG} \mathrm{IBW}_{\mathrm{BW}}$ & $63.3 \pm 30.8$ & $0.76(0.70-0.81)$ & $31.0(26.4-35.6)$ & $75(35.0)$ & 46.06 \\
\hline $\mathrm{CrCl} \mathrm{CG}_{\mathrm{AdjBW}}$ & $82.2 \pm 40.9$ & $0.79(0.73-0.84)$ & $12.2(7.9-16.4)$ & $131(61.21)$ & 33.69 \\
\hline $\mathrm{CrCl} \mathrm{CG}_{\mathrm{LBW}}$ & $62.0 \pm 31.2$ & $0.78(0.72-0.83)$ & $32.3(27.9-36.8)$ & $71(33.2)$ & 46.21 \\
\hline $\mathrm{CrCl} \mathrm{CG}_{\text {rounded s } \mathrm{Cr}}$ & $96.5 \pm 41.4$ & $0.76(0.70-0.81)$ & $-2.2(-6.7-2.3)$ & $135(63.1)$ & 67.24 \\
\hline CKD-EPI & $69.7 \pm 28.8$ & $0.72(0.65-0.78)$ & $24.6(19.7-29.5)$ & $102(47.7)$ & 44.04 \\
\hline MDRD & $70.5 \pm 29.6$ & $0.67(0.59-0.74)$ & $23.9(18.7-29.1)$ & $102(47.7)$ & 47.68 \\
\hline $\mathrm{CrCl} \mathrm{CG_{ \text {modified } }}$ & $94.3 \pm 41.4$ & $0.79(0.73-0.84)$ & $0.01(-4.2-4.2)$ & $137(64.0)$ & 30.38 \\
\hline MVA & $83.7 \pm 30.1$ & $0.77(0.71-0.82)$ & $16.1(11.2-21.0)$ & $128(59.8)$ & 30.59 \\
\hline \multicolumn{6}{|l|}{ Diabetes $(n=213)$} \\
\hline $\mathrm{CrCl} C G_{A B W}$ & $94.1 \pm 48.7$ & $0.73(0.66-0.79)$ & $-4.1(-8.9-0.7)$ & $121(56.9)$ & 35.75 \\
\hline $\mathrm{CrCl} \mathrm{CG}_{\mathrm{IBW}}$ & $68.4 \pm 31.3$ & $0.73(0.66-0.79)$ & $21.6(17.2-26.0)$ & $101(47.4)$ & 39.02 \\
\hline $\mathrm{CrCl} \mathrm{CG}_{\mathrm{AdjBW}}$ & $78.7 \pm 36.3$ & $0.77(0.71-0.82)$ & $11.3(7.2-15.4)$ & $131(61.5)$ & 32.36 \\
\hline $\mathrm{CrCl} \mathrm{CG}_{\mathrm{LBW}}$ & $59.3 \pm 27.6$ & $0.76(0.70-0.81)$ & $30.7(26.4-35.0))$ & $80(37.6)$ & 44.21 \\
\hline $\mathrm{CrCl} \mathrm{CG}_{\text {rounded s } \mathrm{Cr}}$ & $82.5 \pm 36.8$ & $0.70(0.62-0.76$ & $7.5(2.9-12.1)$ & $124(58.2)$ & 61.57 \\
\hline CKD-EPI & $73.5 \pm 27.7$ & $0.66(0.58-0.73)$ & $16.5(11.7-21.3)$ & $101(47.4)$ & 39.29 \\
\hline MDRD & $74.3 \pm 28.2$ & $0.61(0.52-0.69)$ & $15.7(10.6-20.7)$ & $100(46.9)$ & 42.62 \\
\hline $\mathrm{CrCl} \mathrm{CG}$ modified & $90.2 \pm 37.4$ & $0.76(0.70-0.81)$ & $0.1(-4.0-4.3)$ & $129(60.6)$ & 28.96 \\
\hline MVA & $80.2 \pm 27.4$ & $0.77(0.71-0.82)$ & $4.1(-0.7-8.9)$ & $128(60.1)$ & 29.71 \\
\hline \multicolumn{6}{|c|}{ Dyslipidemia $(n=149)$} \\
\hline $\mathrm{CrCl} C G_{\mathrm{TBW}}$ & $91.9 \pm 51.1$ & $0.75(0.67-0.81)$ & $-6.7(-12.3--1.1)$ & $91(61.1)$ & 35.07 \\
\hline $\mathrm{CrCl} \mathrm{CG} \mathrm{BBW}_{\mathrm{BW}}$ & $63.1 \pm 29.2$ & $0.75(0.67-0.81)$ & $22.2(17.1-27.2)$ & $72(48.3)$ & 38.29 \\
\hline $\mathrm{CrCl} C \mathrm{G}_{\mathrm{AdjBW}}$ & $74.6 \pm 36.4$ & $0.78(0.71-0.84)$ & $10.6(5.9-15.4)$ & $95(63.8)$ & 30.76 \\
\hline $\mathrm{CrCl} C G_{L B W}$ & $56.3 \pm 27.8$ & $0.78(0.71-0.84)$ & $29.0(24.0-33.9)$ & $55(36.9)$ & 41.97 \\
\hline $\mathrm{CrCl} C \mathrm{CG}_{\text {rounded s } \mathrm{Cr}}$ & $81.0 \pm 38.0$ & $0.72(0.63-0.79)$ & $4.3(-1.0-9.6)$ & $95(63.8)$ & 58.70 \\
\hline CKD-EPI & $68.8 \pm 26.7$ & $0.67(0.57-0.75)$ & $16.5(10.8-22.1)$ & $76(51.0)$ & 38.52 \\
\hline MDRD & $70.3 \pm 27.4$ & $0.62(0.51-0.71)$ & $15.0(9.0-20.9)$ & $76(51.0)$ & 41.29 \\
\hline $\mathrm{CrCl} \mathrm{CG}$ modified & $84.6 \pm 37.5$ & $0.79(0.72-0.84)$ & $-0.6(-5.3-4.0)$ & $101(67.8)$ & 27.70 \\
\hline MVA & $76.5 \pm 27.8$ & $0.78(0.71-0.84)$ & $6.7(1.1)$ & $98(65.8)$ & 27.22 \\
\hline
\end{tabular}

Abbreviations: AdjBW adjusted body weight, CG Cockcroft-Gault, CrCl creatinine clearance, $L B W$ lean body weight, $R M S E$ root mean square error, $T B W$ total body weight

[37]. There are potential sources of bias when using 24-h $\mathrm{CrCl}$ as the reference value including errors in urine collection, increased creatinine secretion, and increased extrarenal degradation [38]. For example up to $20 \%$ of creatinine is not cleared through the kidney but rather through active secretion. This inherent bias will be present in any method using $\mathrm{sCr}$ in its estimation of GFR. Nonetheless, this strategy represents the most accurate 
clinically used method for measuring $\mathrm{CrCl}$ as an estimate of GFR. Second, we excluded patients with very high $(>2.5 \mathrm{mg} / \mathrm{dL})$ or low $(0.6 \mathrm{mg} / \mathrm{dL})$ serum creatinine and those with a $24-\mathrm{h}$ urine $\mathrm{CrCl}<10 \mathrm{~mL} / \mathrm{min}$; therefore, extrapolating our results to these populations may not be appropriate. Regardless, drug dosing in patients in these extremes should be based on clinical context rather than calculated $\mathrm{CrCl}$ alone. The population age in this study was between (18 to 94years) and included a large proportion of patients over the age of 65 years (43.8\%). While this limits the external application to a younger population, advanced age represents a special population at an increased risk of drug toxicity. Renal impairment is frequently reported in older patients experiencing drug related iatrogenesis and improved assessment of renal function in this population is highly relevant. Moreover, hospitalized patients are often of advanced age and this population is more likely to have reduced $\mathrm{CrCl}$ requiring dosage adjustment. Finally, as with any retrospective study there is potential for information bias. Despite these limitations our findings provide important information for the clinician. Total body weight is the appropriate body weight descriptor to use in the Cockcroft-Gault equation to calculate $\mathrm{CrCl}$. Using adjusted body weight is reasonable in individuals with obesity but provides modest benefit. Our modified Cockcroft-Gault equation using lean body weight outperforms all current methods and warrants further evaluation and validation.

Given that half of all medications or their metabolites are cleared by the kidney and roughly 3 billion prescriptions for medications are written annually many individuals may be at risk for underdosing (or overdosing) if renal function isn't appropriately assessed [39, 40]. While renal dysfunction places patients at risk for adverse events when dosing is not appropriately adjusted, [41] dosage reductions when not necessary may increase risk of treatment failure which is especially concerning with antibiotics or chemotherapeutic agents [42]. Moreover, inaccurate assessment of renal function may influence patient selection in clinical trials [43]. Underestimation of $\mathrm{CrCl}$ may therefore exclude potential clinical trial candidates. Currently, FDA draft guidance for assessment of renal function in pharmacokinetic studies does not indicate a preference as to which formula is used to estimate kidney function [44]. Overall, clinicians should consider the patient population to determine the best strategy to assess renal function. In the clinical setting, determination of renal function to select a drug or drug dosing should not be done with the renal function estimate alone (i.e. Cockcroft-Gault), but rather an assessment of the clinical situation and repercussions for under or over dosing of the medication.
Further research is warranted to identify novel biomarkers to accurately estimate $\mathrm{CrCl}$. Despite improvement of estimation using a modification of the Cockcroft-Gault or development of new equations using nonlinear regression to estimate $\mathrm{CrCl}$, there remains residual error that cannot be explained. This error may be related to inherent limitations of using serum creatinine in the equations (extrarenal degradation and tubular secretion). Future studies should aim at identification of biomarkers that can accurately estimate renal function.

\section{Conclusions}

Based on our study, total body weight is the appropriate weight descriptor to use in the original Cockcroft-Gault equation. Our modified Cockcroft-Gault equation using lean body weight outperforms other methods of calculating $\mathrm{CrCl}$ in terms of correlation, accuracy, mean bias, and RMSE value. Additional research is warranted to determine if this equation is correlated to drug exposure, toxicity, and efficacy.

\section{Abbreviations \\ AdjBW: Adjusted body weight; BMI: Body mass index; CKD-EPI: Chronic Kidney Disease Epidemiology Collaboration; $\mathrm{CrCl}$ : Creatinine clearance; FDA: Food and drug administration; GFR: Glomerular filtration rate; LBW: lean body weight; MDRD: Modified Diet in Renal Disease; MVA: Multivariate; RMSE: Root mean square error; TBW: Total body weight.}

\section{Acknowledgements}

We thank the information technology team for their support in extracting required data.

\section{Authors' contributions}

$L B, L K, U J$ designed the study and extracted data. $L B, H B$, and SY analyzed the data and prepared tables and figures. LB drafted the manuscript. All authors critically reviewed, revised, and approved the final manuscript.

\section{Funding}

Drs. Kagan and Brunetti report grant funding from the National Institute of General medicine of the National Institutes of Health under award number R01 GM124046-01A1.

\section{Availability of data and materials}

The datasets used during the current study are available from the corresponding author on reasonable request.

\section{Declarations}

\section{Ethics approval and consent to participate}

This study was approved at each site's Institutional Review Board (Robert Wood Johnson University Hospital Somerset IRB19-32 and Rutgers Biomedical and Health Sciences Pro2019001862). Each site's Institutional Review Board approved a waiver of consent to access administrative records for this study. All methods were carried out in accordance with relevant guidelines and regulations.

\section{Consent for publication}

Not applicable.

\section{Competing interests}

The authors declare that they have no competing interests. 


\section{Author details}

${ }^{1}$ Department of Pharmacy Practice; Ernest Mario School of Pharmacy; Rutgers, The State University of New Jersey, Piscataway, NJ, USA. ${ }^{2}$ Department of Pharmaceutics; Ernest Mario School of Pharmacy; Rutgers, The State University of New Jersey, Piscataway, NJ, USA. ${ }^{3}$ Center of Excellence in Pharmaceutical Translational Research and Education; Ernest Mario School of Pharmacy; Rutgers, The State University of New Jersey, Piscataway, NJ, USA. ${ }^{4}$ Lake Erie College of Osteopathic Medicine, Erie, PA, USA.

Received: 16 February 2021 Accepted: 27 October 2021

Published online: 22 November 2021

\section{References}

1. Cockcroft DW, Gault MH. Prediction of creatinine clearance from serum creatinine. Nephron. 1976;16(1):31-41.

2. Hales CM, Fryar CD, Carroll MD, Freedman DS, Ogden CL. Trends in obesity and severe obesity prevalence in US youth and adults by sex and age, 2007-2008 to 2015-2016. JAMA. 2018;319(16):1723-5.

3. Allen JA: Chronic Demyelinating Polyneuropathies. Continuum (Minneap Minn) 2017, 23(5, Peripheral Nerve and Motor Neuron Disorders):1310-1331.

4. Lin J, Thompson TJ, Cheng YJ, Zhuo X, Zhang P, Gregg E, et al. Projection of the future diabetes burden in the United States through 2060. Popul Health Metrics. 2018;16(1):9.

5. Schaeffner ES, Kurth T, Curhan GC, Glynn RJ, Rexrode KM, Baigent C, et al. Cholesterol and the risk of renal dysfunction in apparently healthy men. J Am Soc Nephrol. 2003;14(8):2084-91.

6. Hattori M, Nikolic-Paterson DJ, Miyazaki K, Isbel NM, Lan HY, Atkins RC, et al. Mechanisms of glomerular macrophage infiltration in lipid-induced renal injury. Kidney Int Suppl. 1999;71:S47-50.

7. Hirata Y, Nomura K, Senga Y, Okada Y, Kobayashi K, Okamoto S, et al. Hyperglycemia induces skeletal muscle atrophy via a WWP1/KLF15 axis. JCl Insight. 2019;4:4.

8. Perry BD, Caldow MK, Brennan-Speranza TC, Sbaraglia M, Jerums G, Garnham A, et al. Asrar UI Haq M, hare DL et al: muscle atrophy in patients with type 2 diabetes mellitus: roles of inflammatory pathways, physical activity and exercise. Exerc Immunol Rev. 2016;22:94-109.

9. Ariano RE, Zelenitsky SA, Poncsak KR, Davis JC, Vercaigne LM. No role for patient body weight on renal function assessment for drug dosing. J Antimicrob Chemother. 2017;72(6):1802-11.

10. Higdon EA, Kimmons LA, Duhart BT Jr, Hudson JQ. Disagreement in estimates of kidney function for drug dosing in obese inpatients. J Pharm Pract. 2019;32(1):41-7.

11. Winter MA, Guhr KN, Berg GM. Impact of various body weights and serum creatinine concentrations on the bias and accuracy of the Cockcroft-Gault equation. Pharmacotherapy. 2012;32(7):604-12.

12. Demirovic JA, Pai AB, Pai MP. Estimation of creatinine clearance in morbidly obese patients. Am J Health Syst Pharm. 2009;66(7):642-8.

13. Khuu T, Bagdasarian G, Leung J, Nguyen N, Lam LD, Han EE, et al. Estimating aminoglycoside clearance and creatinine clearance in underweight patients. Am J Health Syst Pharm. 2010;67(4):274-9.

14. Nix DE, Mayersohn M, Erstad BL. Should estimates of glomerular filtration rate and creatinine clearance be indexed to body surface area for drug dosing? Am J Health Syst Pharm. 2017;74(21):1814-9.

15. Lau AH, Berk SI, Prosser T, Stonich T. Estimation of creatinine clearance in malnourished patients. Clin Pharm. 1988;7(1):62-5.

16. Scappaticci GB, Regal RE. Cockcroft-Gault revisited: new de-liver-ance on recommendations for use in cirrhosis. World J Hepatol. 2017;9(3):131-8.

17. Nguyen T, Foster Y, Cekaj S. Older adult kidney function assessment and rounding Creatinine led to medication dosing error. Am J Ther. 2018;25(4):e439-46.

18. Berns JS. Clinical decision making in a patient with stage 5 CKD--is eGFR good enough? Clin J Am Soc Nephrol. 2015;10(11):2065-72.

19. Park EY, Kim TY. Where are cut-off values of serum creatinine in the setting of chronic kidney disease? Kidney Int. 2010;77(7):645-6.

20. Tattersall J, Dekker F, Heimburger O, Jager KJ, Lameire N, Lindley E, et al. When to start dialysis: updated guidance following publication of the initiating Dialysis early and late (IDEAL) study. Nephrol Dial Transplant. 2011;26(7):2082-6.

21. Devine B. Gentamicin pharmacokinetics. Drug Intell Clin Pharm. 1974;8:650-5.

22. Chow S, Salmasi G, Callum JL, Lin Y. Trimming the fat with an IVIG approval process. Transfus Apher Sci. 2012;46(3):349-52.

23. Debernard L, Melzer TR, Van Stockum S, Graham C, Wheeler-Kingshott CA, Dalrymple-Alford JC, et al. Reduced grey matter perfusion without volume loss in early relapsing-remitting multiple sclerosis. J Neurol Neurosurg Psychiatry. 2014;85(5):544-51.

24. Janmahasatian S, Duffull SB, Ash S, Ward LC, Byrne NM, Green B. Quantification of lean bodyweight. Clin Pharmacokinet. 2005;44(10):1051-65.

25. Hume R. Prediction of lean body mass from height and weight. J Clin Pathol. 1966;19(4):389-91.

26. Stevens LA, Levey AS. Measured GFR as a confirmatory test for estimated GFR. J Am Soc Nephrol. 2009;20(11):2305-13.

27. Boer P. Estimated lean body mass as an index for normalization of body fluid volumes in humans. Am J Phys. 1984;247(4 Pt 2):F632-6.

28. Levey AS, Bosch JP, Lewis JB, Greene T, Rogers N, Roth D. A more accurate method to estimate glomerular filtration rate from serum creatinine: a new prediction equation. Modification of diet in renal disease study group. Ann Intern Med. 1999;130(6):461-70.

29. Levey AS, Coresh J, Greene T, Stevens LA, Zhang YL, Hendriksen S, et al. Chronic kidney disease epidemiology C: using standardized serum creatinine values in the modification of diet in renal disease study equation for estimating glomerular filtration rate. Ann Intern Med. 2006;145(4):247-54.

30. Levey AS, Stevens LA, Schmid CH, Zhang YL, Castro AF 3rd, Feldman HI, et al. A new equation to estimate glomerular filtration rate. Ann Intern Med. 2009;150(9):604-12.

31. Jones GR, Imam SK. Validation of the revised MDRD formula and the original Cockcroft and Gault formula for estimation of the glomerular filtration rate using Australian data. Pathology. 2009;41(4):379-82.

32. Caruso D, De Santis D, Rivosecchi F, Zerunian M, Panvini N, Montesano $M$, et al. Lean body weight-tailored iodinated contrast injection in obese patient: Boer versus James formula. Biomed Res Int. 2018;2018:8521893.

33. Smythe M, Hoffman J, Kizy K, Dmuchowski C. Estimating creatinine clearance in elderly patients with low serum creatinine concentrations. Am J Hosp Pharm. 1994;51(2):198-204.

34. Rigalleau V, Lasseur C, Perlemoine C, Barthe N, Raffaitin C, Liu C, et al. Estimation of glomerular filtration rate in diabetic subjects: Cockcroft formula or modification of diet in renal disease study equation? Diabetes Care. 2005;28(4):838-43

35. Bluher M. Obesity: global epidemiology and pathogenesis. Nat Rev Endocrinol. 2019;15(5):288-98.

36. Lin $X, X u Y$, Pan $X, X u$ J, Ding $Y$, Sun $X$, et al. Global, regional, and national burden and trend of diabetes in 195 countries and territories: an analysis from 1990 to 2025. Sci Rep. 2020;10(1):14790.

37. Shahbaz H, Gupta M. Creatinine Clearance. [Updated 2020 Sep 2]. In: StatPearls [Internet]. Treasure Island (FL): StatPearls Publishing; 2021 Jan-. Available from: https://www.ncbi.nlm.nih.gov/books/NBK544228/.

38. Payne RB. Creatinine clearance: a redundant clinical investigation. Ann Clin Biochem. 1986:23(Pt 3):243-50.

39. Corsonello A, Pedone C, Corica F, Mussi C, Carbonin P, Antonelli Incalzi R. Gruppo Italiano di Farmacovigilanza nell'Anziano I: concealed renal insufficiency and adverse drug reactions in elderly hospitalized patients. Arch Intern Med. 2005:165(7):790-5.

40. Hansen RJ, Balthasar JP. Pharmacokinetic/pharmacodynamic modeling of the effects of intravenous immunoglobulin on the disposition of antiplatelet antibodies in a rat model of immune thrombocytopenia. J Pharm Sci. 2003;92(6):1206-15

41. Yap C, Dunham D, Thompson J, Baker D. Medication dosing errors for patients with renal insufficiency in ambulatory care. Jt Comm J Qual Patient Saf. 2005;31(9):514-21.

42. Bassetti M, Montero JG, Paiva JA. When antibiotic treatment fails. Intensive Care Med. 2018:44(1):73-5.

43. Casal MA, Nolin TD, Beumer JH. Estimation of kidney function in oncology: implications for anticancer drug selection and dosing. Clin J Am Soc Nephrol. 2019;14(4):587-95. 
44. US Department of Health and Human Services Food and Drug Administration: Draft Guidance for Industry_-Pharmacokinetics in Patients with Impaired Renal Function, Rockville, MD, US Department of Health and Human Services Food and Drug Administration Center for Drug Evaluation, 2010.

\section{Publisher's Note}

Springer Nature remains neutral with regard to jurisdictional claims in published maps and institutional affiliations.

- fast, convenient online submission

- thorough peer review by experienced researchers in your field

- rapid publication on acceptance

- support for research data, including large and complex data types

- gold Open Access which fosters wider collaboration and increased citations

- maximum visibility for your research: over 100M website views per year

At BMC, research is always in progress.

Learn more biomedcentral.com/submissions 